South Dakota State University

Open PRAIRIE: Open Public Research Access Institutional

Repository and Information Exchange

Mechanical Engineering Engineering Faculty

Publications

Department of Mechanical Engineering

$7-2014$

Biomechanical Evaluation of fracture Fixation Constructs using a Variable-angle Locked Periprosthetic Femur Plate System

Martin F. Hoffmann

Travis A. Burgers

James J. Mason

Bart O. Williams

Debra L. Sietsema

Follow this and additional works at: https://openprairie.sdstate.edu/me_pubs

Part of the Biomedical Engineering and Bioengineering Commons 


\title{
Biomechanical Evaluation of Fracture Fixation Constructs Using a Variable- Angle Locked Periprosthetic Femur Plate System
}

\author{
Martin F. Hoffmann, $\mathrm{MD}^{1,2,3,4}$; Travis A. Burgers, $\mathrm{PhD}^{1}$; James J. Mason, $\mathrm{PhD}^{1}$; Bart O. Williams, $\mathrm{PhD}^{1}$; \\ Debra L. Sietsema, $\mathrm{PhD}^{1,3}$; Clifford B. Jones, $\mathrm{MD}^{1,3}$ \\ 1 Van Andel Research Institute, Grand Rapids, MI, USA; \\ 2 Grand Rapids Medical Education Partners, Grand Rapids, MI, USA; \\ 3 Orthopaedic Associates of Michigan, Grand Rapids, MI, USA; \\ 4 Department of Surgery, BG-University Hospital Bergmannsheil, Ruhr-University Bochum, Germany \\ Corresponding author:
}

Martin F. Hoffmann, MD Department of Surgery, BG-University Hospital Bergmannsheil Bürkle-de-laCamp-Platz 1, 44789 Bochum Germany, Phone: +49 234 302-3391, E-mail: martinfhoffmann@ gmx.net

\begin{abstract}
Background

In the United States there are more than 230,000 total hip replacements annually, and periprosthetic femoral fractures occur in $0.1-4.5 \%$ of those patients. The majority of these fractures occur at the tip of the stem (Vancouver type B1). The purpose of this study was to compare the biomechanically stability and strength of three fixation constructs and identify the most desirable construct.
\end{abstract}

Methods

Fifteen medium adult synthetic femurs were implanted with a hip prosthesis and were osteotomized in an oblique plane at the level of the implant tip to simulate a Vancouver type B1 periprosthetic fracture. Fractures were fixed with a non-contact bridging periprosthetic proximal femur plate (Zimmer, Inc., Warsaw, IN). Three proximal fixation methods were used: Group 1, bicortical screws; Group 2, unicortical screws and one cerclage cable; and Group 3, three cerclage cables. Distally, all groups had bicortical screws. Biomechanical testing was performed using an axial-torsional testing machine in three different loading modalities (axial compression, lateral bending, and torsional/sagittal bending), next in axial cyclic loading to 10,000 cycles, again in the three loading modalities, and finally to failure in torsional/sagittal bending.

Results

Group 1 had significantly greater load to failure and was significantly stiffer in torsional/sagittal bending than Groups 2 and 3. After cyclic loading, Group 2 had significantly greater axial stiffness than Groups 1 and 3. There was no difference between the three groups in lateral bending stiffness. The average energy absorbed during cyclic loading was significantly lower in Group 2 than in Groups 1 and 3.

Conclusions

Bicortical screw placement achieved the highest load to failure and the highest torsional/sagittal bending stiffness. Additional unicortical screws improved axial stiffness when using cable fixation. Lateral bending was not influenced by differences in proximal fixation.

Clinical Relevance

To treat periprosthetic fractures, bicortical screw placement should be attempted to maximize load to failure and torsional/sagittal bending stiffness.

\section{Keywords}

Total hip replacement, periprosthetic, fracture, plate, locked angle, biomechanics 


\section{Introduction}

Total hip replacement is one of the most common orthopedic procedures in the United States, with more than 230,000 total hip replacements performed each year ${ }^{22}$. Complications to these procedures, even if they are uncommon, result in severe morbidity and mortality ${ }^{32}$. Periprosthetic femoral fractures occur in $0.1-4.5 \%$ of all patients who have primary total hip arthroplasty $1,8,17,19,28,36,39$. Due to higher activity of individuals' lifestyles and the incidence of osteoporosis, the number of periprosthetic fractures is likely to increase ${ }^{29,30}$. Revision surgery has an even higher incidence of such fractures ${ }^{12,26,39}$, from $3.6 \%$ for cemented prostheses to $20.9 \%$ for uncemented prostheses ${ }^{46}$. Thus, some 10,000 periprosthetic femur fractures need treatment annually, mostly in patients with additional risk factors and osteopenia ${ }^{47}$.

Osteoporotic patients with total hip replacements are additionally affected by biological and mechanical issues. These issues commonly include multiple medical co-morbidities, multiple fracture planes with lowerenergy injuries, and difficulty with postoperative mobilization ${ }^{4,21}$. Replacement arthroplasty has a high incidence of serious complications ${ }^{7}$. Closed treatment of femoral fractures has been historically recommended ${ }^{11,23}$, but it is associated with many problems and complications due to prolonged bed rest ${ }^{11}$, loss of motion ${ }^{41}$, and non-union or malunion ${ }^{7,41}$. Malunion is particularly troubling in the context of total hip or knee prosthesis because fracture malalignment can accelerate loosening and revision surgery is more difficult with a femur that has healed in a deformed state ${ }^{6}$. Most recently, treatment has focused on open reduction with internal fixation ${ }^{33}$.

The majority (75\%) of periprosthetic fractures following total hip arthroplasty occur at the tip of the stem (Vancouver type $\mathrm{B}^{4}$, Cooke type $\left.\mathrm{III}^{42}\right)^{9,27}$. These are the most complex to treat and have high complication rates $^{2,24}$. One of the goals of treatment for this injury pattern is the achievement of fracture union while retaining the proper function of the prosthesis ${ }^{47}$. Fixation of periprosthetic femur fractures after total hip replacement remains a challenge, especially around stable femoral components. For conventional plate fixations, the placement of bicortical screws around a stem is usually impossible. Cable and plate fixation using cerclage cables about the proximal fragment and bicortical screws for fixation of the distal fragment (Ogden construct) avoids the problem of screw placement ${ }^{14}$. However, plate constructs using unicortical screw fixation for the proximal fragment have been demonstrated to be superior to proximal cable fixation ${ }^{15,25}$. Locked plating has been found to be stiffer than cable plate fixation ${ }^{20}$. From our standpoint, the use of allograft struts ${ }^{14}$ develops its advantage especially during healing and incorporation, but it requires extensive disruption of periosteal soft tissues, which can adversely affect fracture healing ${ }^{6}$. Most recently, periprosthetic plates have been introduced that allow screws to be angled around the implant proximally with bicortical screw purchase in the femoral shaft. We hypothesize that angling the screws around the implant shaft and bicortical purchase in these new periprosthetic plates will cause the bone-implant construct to be stronger than unicortical and cable fixation constructs.

\section{Materials and Methods}

In our study, 15 medium adult synthetic left femurs (Fourth Generation Composite Femur, model 3403; Sawbones Worldwide, Vashon, WA) were used, because synthetic femurs have less interspecimen variability of physical properties than human cadaveric bone ${ }^{10,29}$. Each femur was implanted with a hip prosthesis (13 mm Uncemented Hip VerSys ${ }^{\circledR}$ Fiber Metal MidCoat Collarless Standard Offset, Zimmer, Inc., Warsaw, IN). The femurs were osteotomized with an oscillating saw in an oblique plane (45 degrees to the shaft axis superolateral to inferior medial) at the level of the implant tip to simulate a periprosthetic fracture, Vancouver type B1 (Cooke type III), OTA 32A2. A gap of $5 \mathrm{~mm}$ was created ${ }^{47}$ and fracture fixation was performed using a left 12-hole $(285 \mathrm{~mm})$, non-contact bridging, periprosthetic proximal femur plate (NCB ${ }^{\circledR}$ Plating System, Zimmer, Inc., Warsaw, IN). This condition approximates fixation conditions immediately after surgery at the early healing stage, where interfragmentary stiffness is negligible and the construct stiffness is dependent on implant fixation ${ }^{5}$. Screw placement was performed according to the manufacturer's recommendations, considering that the design of the NCB plate (Zimmer, Inc., Warsaw, IN) allows approximately $30^{\circ}$ multidirectional-locked screw placement angling the screws around the implant shaft in an unlocked manner followed by locking utilizing locking-caps, as well as cable fixation.

The fifteen samples were randomly assigned to one of three groups. Groups were chosen based on the 
common recommendation that at least six cortices be traversed by the screws used in any fracture fixation ${ }^{16,34,38}$, and in an effort to evaluate the use of cerclage (which is typically less than desirable in any fracture fixation). Distally, all groups had three $4 \mathrm{~mm}$ bicortical locking screws, according to biomechanical recommendations ${ }^{13}$. The groups differed in their proximal fixation (Figure 1).

1. Proximal six $4 \mathrm{~mm}$ bicortical angled locked screws full contact.

2. Proximal cerclage (1+1 NCB $\circledR$ Locking Plate Cable Button) and four unicortical $5 \mathrm{~mm}$ screws.

3. Proximal three cerclages (Cable Assembly Cerclage, $1.8 \mathrm{~mm}$ ).

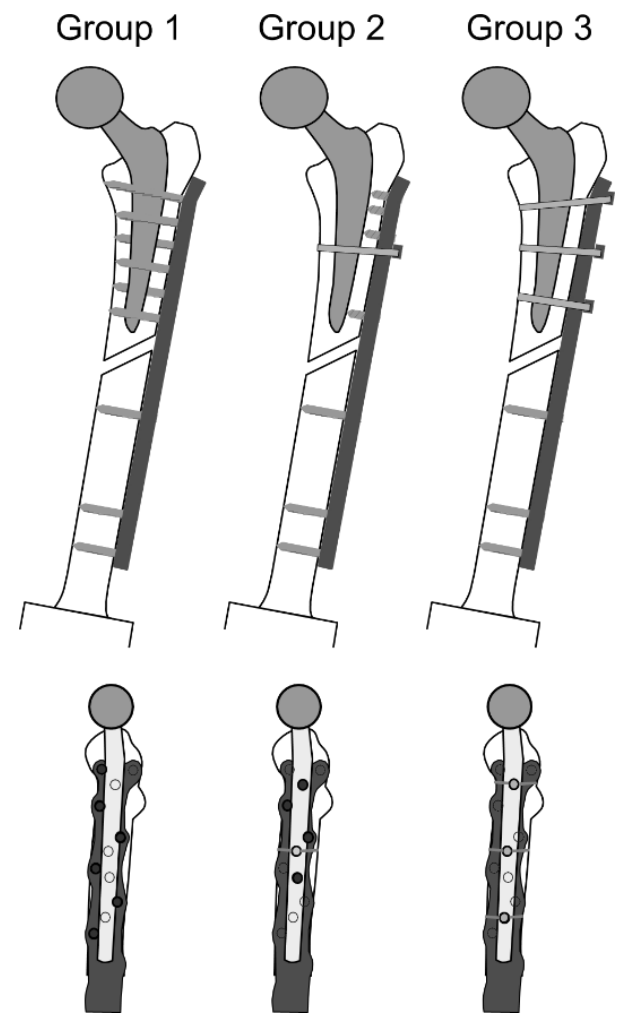

Figure 1: Schematic of periprosthetic fixation constructs. Top, frontal view; bottom, lateral view of proximal segment. Group 1, bicortical proximal screws; Group 2, unicortical proximal screws plus cable; Group 3, proximal cable fixation.

Each construct was oriented to mimic the femur anatomical orientation at approximately $10^{\circ}$ adduction in the frontal plane and vertically in the sagittal plane. Previous studies have used a $25^{\circ}$ orientation in the frontal plane ${ }^{14,15,47}$, but in this setup, axial loading opened the fracture gap instead of closing it. The femoral condyles were removed and the shaft was potted in a low-temperature casting alloy (bismuth alloy, part 8921K12, McMaster-Carr Supply Company, Robbinsville, NJ) and clamped into a vice (Figure 2). Load was applied through the implant head using a flat plate. Two preconditioning cycles were applied using an axial-torsional universal testing machine (830L system, TestResources, Shakopee, MN) from $50 \mathrm{~N}$ to $450 \mathrm{~N}$ at $20 \mathrm{~N} / \mathrm{s}$, and then a preload of $10 \mathrm{~N}$ was maintained on the sample. The construct was loaded to $500 \mathrm{~N}^{14,47}$ at $20 \mathrm{~N} / \mathrm{s}$ (approximately $0.04 \mathrm{~mm} / \mathrm{s}$ ) in axial compression.

The construct was then fixed into the vice horizontally to apply lateral flexural bending perpendicular to the weaker cross section of the periprosthetic plate (Figure 2). Load was applied through the implant head using a flat plate. A support block was placed $10 \mathrm{~mm}$ distal to the most proximal of the three screws inserted into the distal fragment (Figure 2). The support was $235 \mathrm{~mm}$ from the center of the implant head. Two preconditioning cycles were applied from $10 \mathrm{~N}$ to $150 \mathrm{~N}$ at $10 \mathrm{~N} / \mathrm{s}$, and a preload of $10 \mathrm{~N}$ was maintained on the sample. The construct was loaded to $250 \mathrm{~N}^{14,47}$ at $10 \mathrm{~N} / \mathrm{s}$ (approximately $2 \mathrm{~mm} / \mathrm{s}$ ) in lateral bending. 

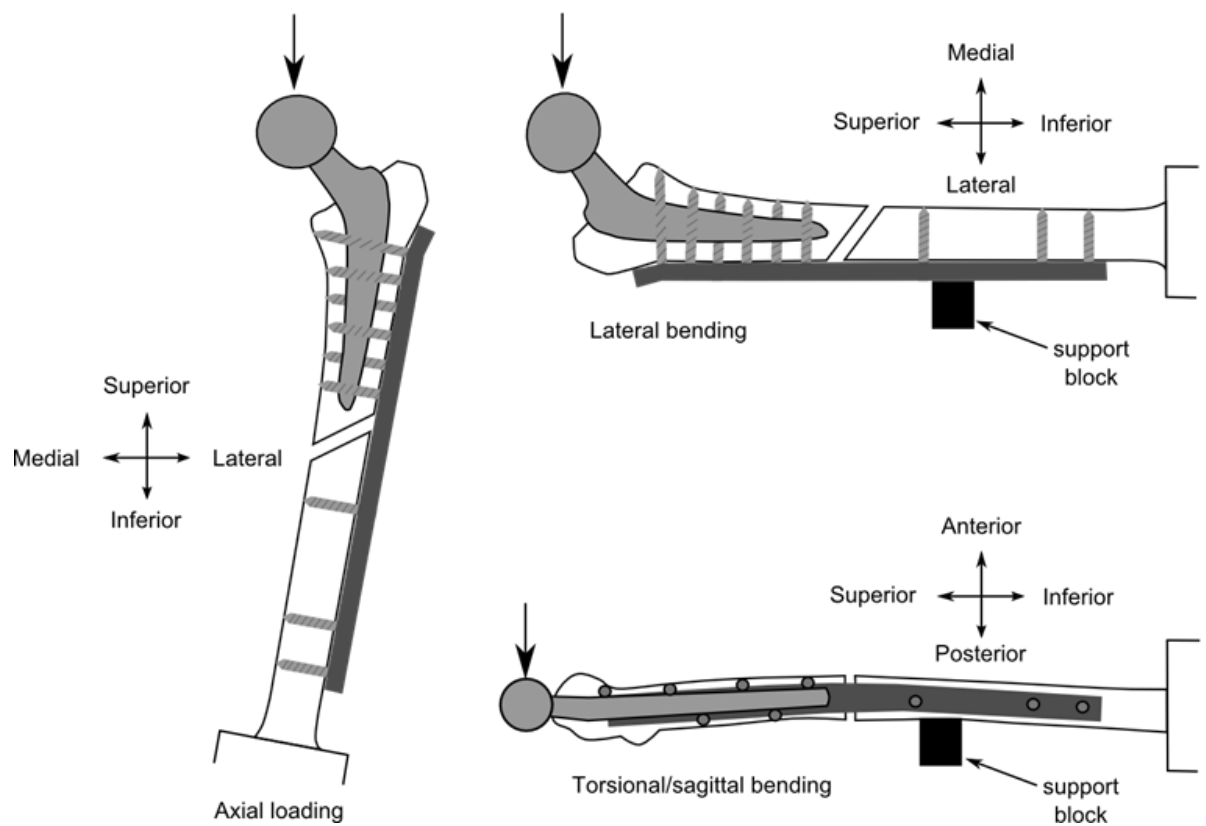

Figure 2: Schematic of the orientation of the constructs in (a) axial loading, (b) lateral bending and (c) torsional/sagittal bending.

The construct was then fixed into the vice horizontally to apply torsional/sagittal bending perpendicular to the stronger cross section of the periprosthetic plate (Figure 2). Load was applied through the implant head using a flat plate. A support block was placed $10 \mathrm{~mm}$ distal to the most proximal of the three screws inserted into the distal fragment (Figure 2). The support was $235 \mathrm{~mm}$ from the center of the implant head; the implant head was $42 \mathrm{~mm}$ from the central axis of the femur. Two preconditioning cycles were applied from $10 \mathrm{~N}$ to $150 \mathrm{~N}$ at $10 \mathrm{~N} / \mathrm{s}$, and a preload of $10 \mathrm{~N}$ was maintained on the sample. The construct was loaded to $200 \mathrm{~N}^{14,47}$ at $10 \mathrm{~N} / \mathrm{s}$ (approximately $0.7 \mathrm{~mm} / \mathrm{s}$ ) in torsion/sagittal bending.

After testing the samples for stiffness in all three modalities, axial cyclic loading (Figure 2) was performed with a load of 50-500 $\mathrm{N}$ at $3 \mathrm{~Hz}$ for 10,000 cycles following a previous study ${ }^{14}$. The load and displacement were recorded every 100th cycle. The energy of each of these cycles was measured as the area inside the force-displacement curve. After cyclic loading, the femurs were again tested in all three modalities. Finally, the specimens were loaded to failure or to a displacement of $10 \mathrm{~cm}$ in torsional/sagittal bending (Figure 2). The failed samples were visually inspected for mode of failure.

The slope of the linear region of the force-displacement curve was used to calculate the stiffness for each quasistatic loading test. All specimens remained in the linear elastic region during loading. Student's paired $t$ tests were performed to compare these slopes and failure loads (Microsoft Excel 2010, Microsoft, Redmond, WA); $p<0.05$ was considered significant. The average and standard deviation are reported.

\section{Results}

There were no failures of the distal fixation. All specimens failed in the proximal segment or the test was ended due to reaching maximum displacement.

\section{Group 1 - Bicortical proximal screws}

The average load to failure was $807 \mathrm{~N}$ (Figure 3). The average energy absorbed per cycle in axial loading was $106 \mathrm{~mJ}$ (Figure 4). Axial stiffness increased significantly due to cyclic loading (530 N/mm after vs. $347 \mathrm{~N} / \mathrm{mm}$ before, $p=0.040$; Figure 5). There was no significant change in lateral bending stiffness $(5.38 \mathrm{~N} / \mathrm{mm}$ after vs. $5.71 \mathrm{~N} / \mathrm{mm}$ before, $p=0.091$; Figure 6$)$ or torsional/sagittal bending stiffness $(17.2 \mathrm{~N} / \mathrm{mm}$ after vs.

$15.3 \mathrm{~N} / \mathrm{mm}$ before, $p=0.12$; Figure 7) due to cyclic loading. In Group 1, one sample had a fracture through the second- and third-most proximal screws, three had fractures in the greater trochanter, and one reached maximum deflection (10 cm; Figure 8). 


\section{Group 2 - Unicortical proximal screws plus cable}

The average load to failure was $630 \mathrm{~N}$ (Figure 3). The average energy absorbed per cycle in axial loading was $69 \mathrm{~mJ}$ (Figure 4). Axial stiffness increased significantly due to cyclic loading ( $478 \mathrm{~N} / \mathrm{mm}$ before, $849 \mathrm{~N} / \mathrm{mm}$ after, $p=0.016$; Figure 5). There was no significant change in lateral bending stiffness $(5.50 \mathrm{~N} / \mathrm{mm}$ before, $5.39 \mathrm{~N} / \mathrm{mm}$ after, $p=0.8$; Figure 6$)$ or torsional/sagittal bending stiffness $(14.3 \mathrm{~N} / \mathrm{mm}$ before, $13.6 \mathrm{~N} / \mathrm{mm}$ after, $p=0.4$; Figure 7) due to cyclic loading. In Group 2, two samples had the second-most proximal screw pull out (Figure 9), two had bone fracture at the location of the second-most proximal screw and had the screw pull out, one had a fracture through the most proximal screw and had the screw pull out, and two had fractures in the greater trochanter (two samples had more than one failure; Figure 8). None of the cables broke in Group 2.

\section{Group 3 - Proximal cable fixation}

The average load to failure was $618 \mathrm{~N}$ (Figure 3). The average energy absorbed per cycle in axial loading was $97 \mathrm{~mJ}$ (Figure 4). There was no significant change in axial stiffness $(570 \mathrm{~N} / \mathrm{mm}$ before, $430 \mathrm{~N} / \mathrm{mm}$ after, $p=0.14$; Figure 5), lateral bending stiffness $(5.73 \mathrm{~N} / \mathrm{mm}$ before, $5.75 \mathrm{~N} / \mathrm{mm}$ after, $p=0.9$; Figure 6$)$ or torsional/sagittal bending stiffness $(14.5 \mathrm{~N} / \mathrm{mm}$ before, $14.7 \mathrm{~N} / \mathrm{mm}$ after, $p=0.8$; Figure 7$)$ due to cyclic loading. In Group 3, all five samples failed when the proximal cable broke. All specimens failed in flexion rather than torsion in the torsion-flexion mode. The implant rotated in the sagittal plane and the most proximal cable broke in shear (Figure 8), which then caused the load to drop. When the test was continued, the further displacement caused more tension on the middle cable and it also broke in shear. The drop in load due to the first cable's failure was considered the point of construct failure.

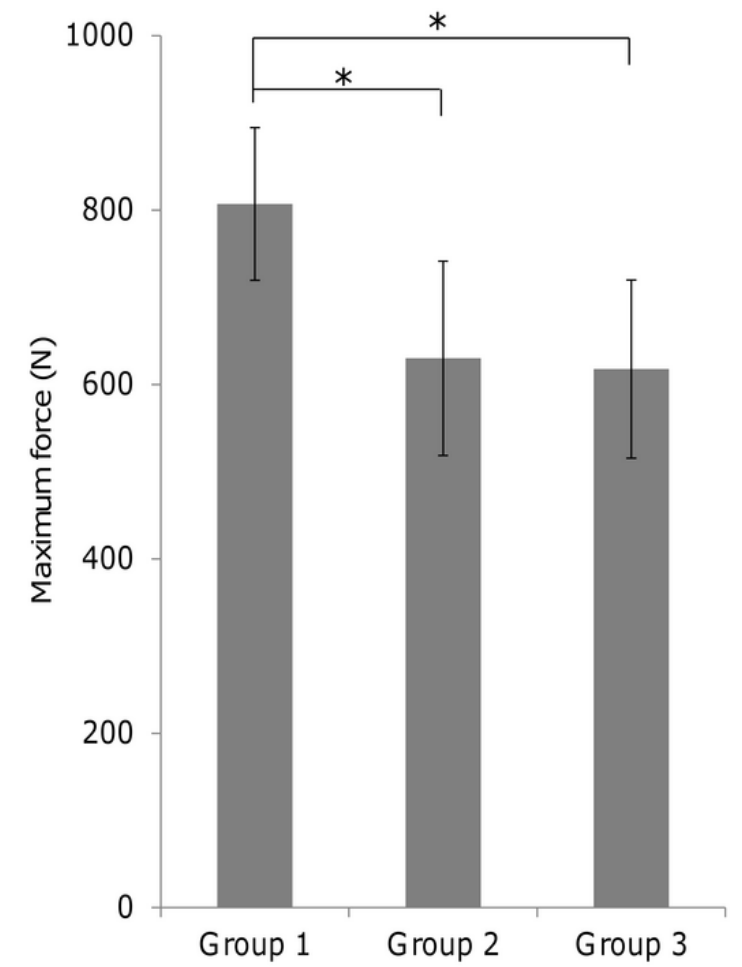

Figure 3: Maximum force at failure in torsional/sagittal bending, $* p<0.05$

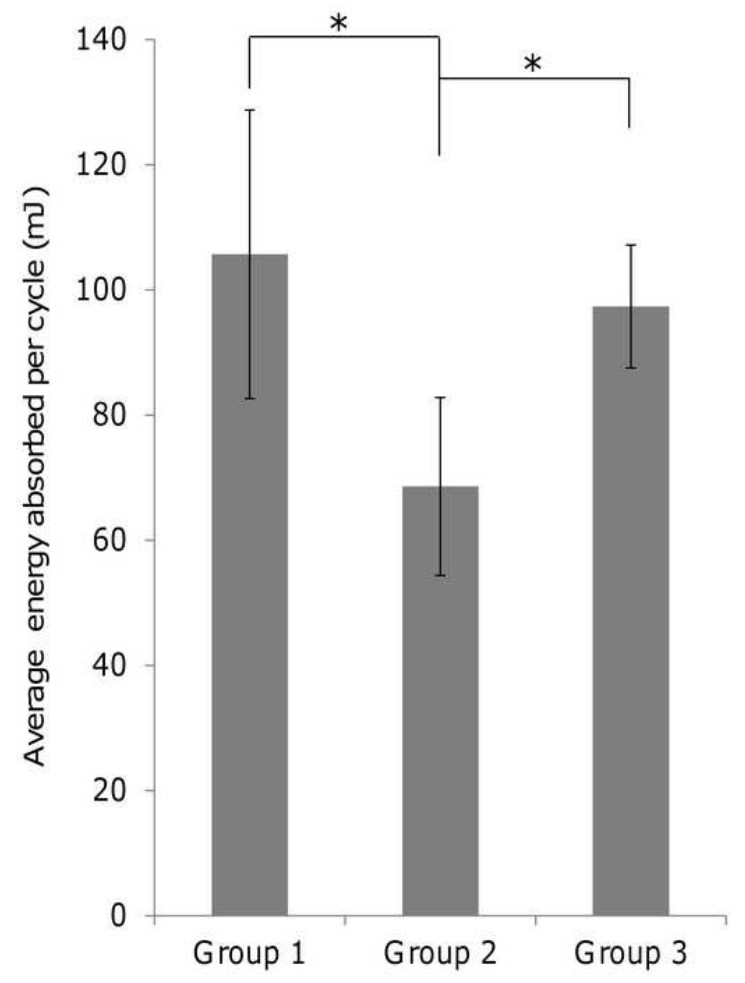

Figure 4: Absorbed energy per cycle in axial loading, $* p<0.05$ 


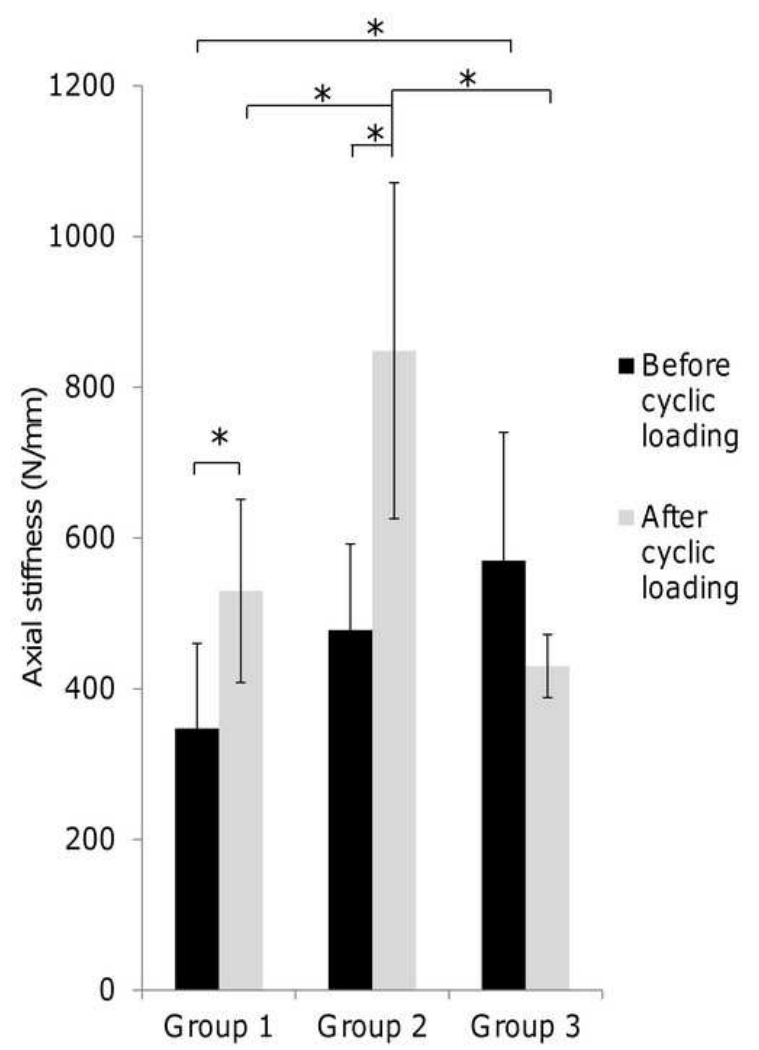

Figure 5: Axial stiffness, $* p<0.05$



Figure 6: Lateral bending stiffness

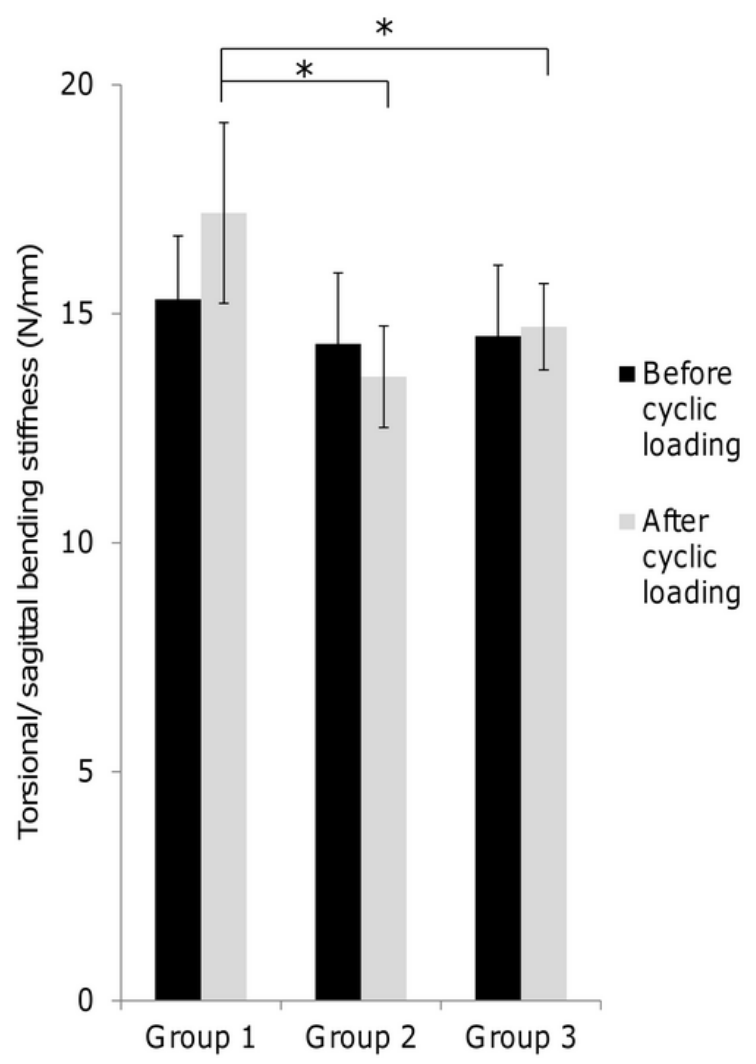

Figure 7: Torsional/sagittal bending stiffness, $* p<0.05$

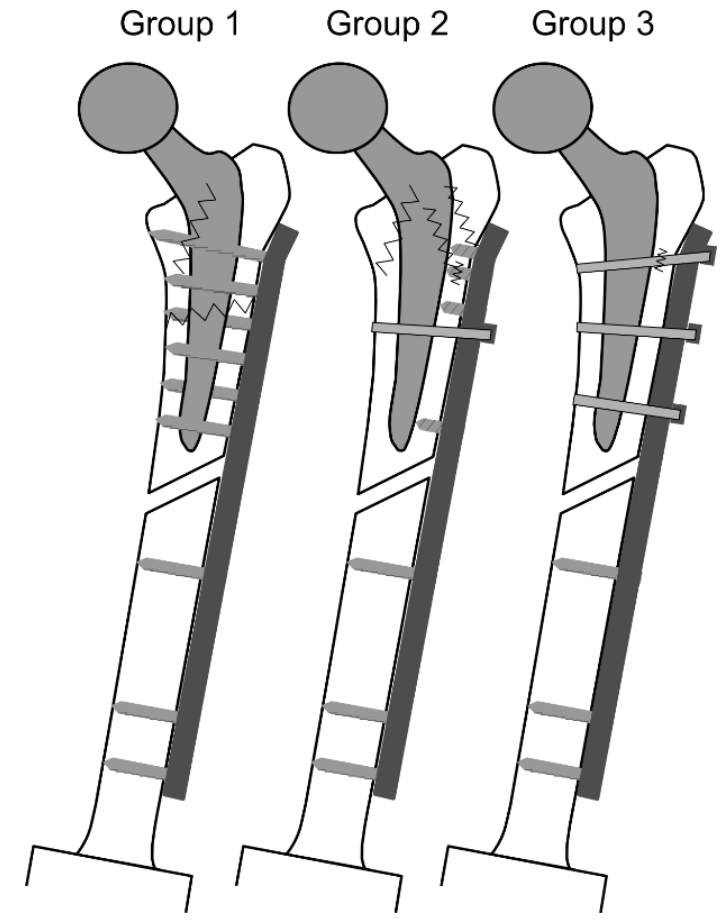

Figure 8: Failure patterns. Saw-toothed lines represent failure locations. 


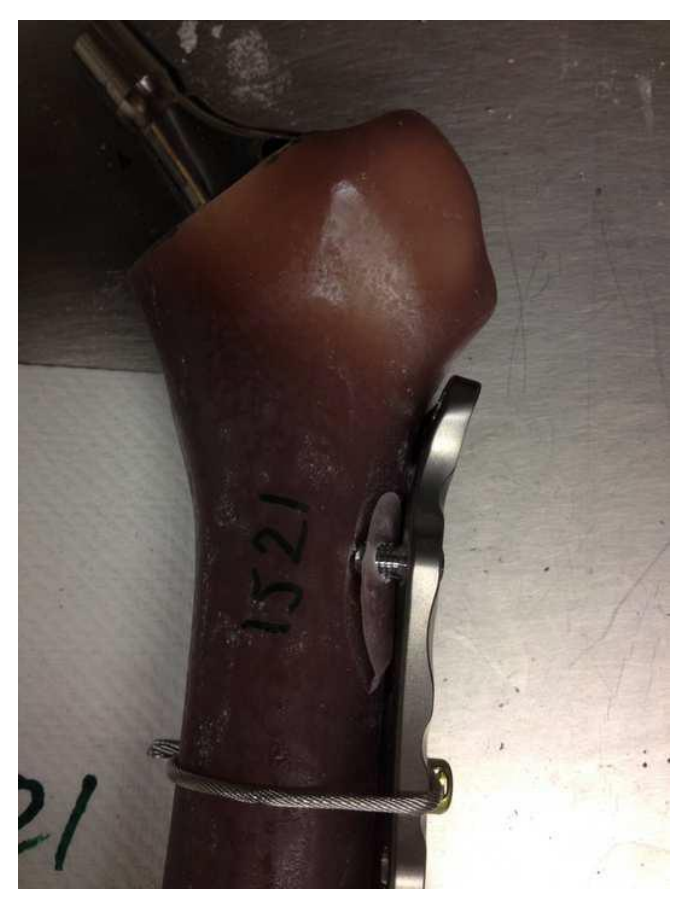

Figure 9: Failure pattern: Unicortical screw pulled out during testing.

\section{Comparison of Groups}

None of the groups failed during cyclic loading or before the load-to-failure test. Group 1 had a significantly greater load to failure than Group $2(p=0.025)$ and Group $3(p=0.014$; Figure 3). There was no difference between the three groups in lateral bending stiffness (Figure 6). Before cyclic loading, Group 3 had significantly greater axial stiffness than Group $1(p=0.045)$; after cyclic loading, Group 2 had significantly greater axial stiffness than Group $1(p=0.030)$ and Group $3(p=0.013$; Figure 5). After cyclic loading, Group 1 was significantly stiffer than Group $2(p=0.011)$ and Group $3(p=0.046)$ in torsional/sagittal bending (Figure 7). The average energy absorbed during cyclic loading was significantly lower in Group 2 than in Group 1 ( $p=0.019$ ) and Group 3 ( $p=0.007$; Figure 4).

The difference in energy absorbed was due to the stiffness of the construct, because Group 2 had the highest post-cyclic loading stiffness. The width of the force-displacement curve mid cycle $(275 \mathrm{~N})$ remained similar over the ten sampled cycles for each specimen as well as each group.

\section{Discussion}

Many risk factors for periprosthetic femoral fracture (PFF) after total hip replacement have been described. Most of them, such as osteoporosis, rheumatoid arthritis, cortical perforation, revision surgery, and component loosening, weaken the femoral bone ${ }^{13}$. Additionally, the fixation and stiffness of the stem creates a different biomechanical scenario in the fracture of an intact femur ${ }^{29}$. A recent biomechanical study showed that the femoral stem itself significantly reduced the fracture strength by $32 \%{ }^{35}$. Therefore, an increase in PFF is to be expected regardless of sufficient treatment for risk factors.

The goal of surgical fracture treatment is to restore early bony stability and complete function of the limb and the patient ${ }^{31}$. The ultimate goals of periprosthetic fracture management are to provide the patient with fracture union, a stable prosthesis, and a functional $\operatorname{limb}^{13}$. Beyond different treatment options and a variety of implants, treatment of Vancouver Type B PFF is still challenging because these fractures involve the bone in the vicinity of the femoral stem ${ }^{29}$. Fractures with a well-fixed stem (Vancouver Type B1) are commonly treated by open reduction and internal fixation ${ }^{32}$. The variety of methods, implants, and their combinations implies that no "gold standard" exists.

It is difficult to achieve the common recommendation that six cortices be traversed by the screws during 
fracture fixation. Placement of bicortical screws around a stem for conventional plate fixation is generally impossible. The difficulty of screw placement in combination with supposedly poor bone quality usually leads to placement of as many screws as possible. New plate designs address this problem with screw holes outside the midline of the plate, allowing angling of the screws (Group 1; Figure 1). The use of cerclages and cables has been controversial. The exclusive use of cerclage generally does not provide enough strength and therefore does not allow functional aftercare, but cerclages may contribute to the long-term stability of periprosthetic fracture fixation when combined with locked plating (Group 3) ${ }^{31}$. An advantage of limiting cable use is the preservation of blood supply and prevention of devitalizing bone and soft tissue at the fracture $\operatorname{site}^{13}$. Locked plating also offers the possibility of unicortical screw fixation with or without cable fixation (Group 2).

We found three sufficient fixation methods for PFF Vancouver Type B1 in this study. None of the groups failed during testing or cyclic loading. The axial stiffness of 347-849 N/mm overlapped with those from other studies in synthetic femurs $(863-930 \mathrm{~N} / \mathrm{mm})^{40}$, but were higher than those from studies using cadaveric femurs $(228-474 \mathrm{~N} / \mathrm{mm})^{14,20}$. In each of the cadaver studies, the femurs were subjected to mechanical testing after they were embalmed, which could decrease the stiffness of the bones ${ }^{45}$.

The increased stiffness of Groups 1 and 2 after the cyclic loading could be attributed to implant seating in the reamed hole despite the fact that all samples underwent two preconditioning cycles with up to $500 \mathrm{~N}^{44}$. Axial stiffness was increased by the combination of cable and unicortical screws. The initial greater axial stiffness of the cable construct was preserved by additional locking screw fixation. Dennis et al. and Lever et al. previously found that unicortical screws were stiffer than cables ${ }^{15,25}$. In a study by Shah et al., unicortical screws in combination with cables resulted in the greatest axial stiffness ${ }^{37}$. Torsional stiffness was significantly greater for bicortical screws, and bicortical screws in this plate increased the maximum load to failure.

All samples failed in the proximal segment (Figure 8). This is in accord with previous findings in finite element models, where high stresses were observed in the proximal part of the femur ${ }^{37}$, and in biomechanical studies, where the ultimate failure occurred because of an oblique crack originating at the most proximal screw $^{47}$. An advantage of cable constructs in our study was that all failures were in the cable with no damage to the bone. Therefore in daily practice, these constructs are most easily revised.

We acknowledge the limitations of our study. This was a biomechanical study performed on synthetic femurs, which are standardized, free of soft tissue, and allow for optimal plate fixation and screw/cable placement. Synthetic femurs were used instead of cadaveric specimens to increase comparability and to avoid inherent variability in bone quality, geometry, and the potential presence of pre-existing damage ${ }^{29}$. The osteotomy gap was created to prevent compressive load-sharing of the bone ends and to isolate the effect of the proximal fixation. Our study focused on stiffness, but this may be misleading ${ }^{29}$ when rigid fixation prevents callus formation ${ }^{43}$ or biological fracture healing. Further, no conclusion can be drawn about biological factors such as blood supply or soft tissue damage. This study does not reflect cemented femoral stems where screw placement can be obstructed by the acrylic cement or additional stability can be achieved by screw purchase in the cement mantle. The majority of periprosthetic fractures usually occur in elderly patients, and the samples in our study do not represent osteoporotic bones. Frequently, treatment of periprosthetic fractures is complicated by osteoporosis and poor quality of the remaining bone ${ }^{13}$.

\section{Conclusions}

New plate designs offer a variety of fixation options that are especially helpful for periprosthetic fractures. In our study, bicortical screw placement achieved maximal load to failure and maximal torsional/sagittal bending stiffness. Lateral bending was not influenced by differences in proximal fixation technique. Additional unicortical screws increased axial stiffness relative to cable fixation alone. The cable construct failed in the cable and there was no damage to the bone; therefore, in daily practice, these constructs are most easily revised.

\section{Acknowledgements}

We thank Zimmer Inc., Warsaw, IN for providing the artificial femurs and all supplies related to the 
orthopedic implants. We thank Andy Vander Moren for his assistance in the biomechanical testing and David Nadziejka for his assistance preparing the manuscript.

\section{References}

1. Adolphson, P.; Jonsson, U.; and Kalen, R.: Fractures of the ipsilateral femur after total hip arthroplasty. Arch Orthop Trauma Surg, 106(6): 353-7, 1987.

2. Beals, R. K., and Tower, S. S.: Periprosthetic fractures of the femur. An analysis of 93 fractures. Clin Orthop Relat Res, (327): 238-46, 1996.

3. Beer, F. P., and Johnston, E. R. J.: Mechanics of Materials. Edited, New York, Mcgraw-Hill College, 1992.

4. Brady, O. H.; Garbuz, D. S.; Masri, B. A.; and Duncan, C. P.: Classification of the hip. Orthop Clin North Am, 30(2): 215-20, 1999.

5. Bredbenner, T. L.; Snyder, S. A.; Mazloomi, F. R.; Le, T.; and Wilber, R. G.: Subtrochanteric fixation stability depends on discrete fracture surface points. Clin Orthop Relat Res, (432): 217-25, 2005.

6. Chandler, H. P., and Tigges, R. G.: The role of allografts in the treatment of periprosthetic femoral fractures. Instr Course Lect, 47: 257-64, 1998.

7. Cooke, P. H., and Newman, J. H.: Fractures of the femur in relation to cemented hip prostheses. $J$ Bone Joint Surg Br, 70(3): 386-9, 1988.

8. Cool, P., and Weidema, W. F.: Proximal femoral fractures in conjunction with hemiarthroplasty according to Moore. Neth J Surg, 40(5): 139-41, 1988.

9. Corten, K.; Vanrykel, F.; Bellemans, J.; Frederix, P. R.; Simon, J. P.; and Broos, P. L.: An algorithm for the surgical treatment of periprosthetic fractures of the femur around a well-fixed femoral component. $J$ Bone Joint Surg Br, 91(11): 1424-30, 2009.

10. Cristofolini, L.; Viceconti, M.; Cappello, A.; and Toni, A.: Mechanical validation of whole bone composite femur models. J Biomech, 29(4): 525-35, 1996.

11. Crotwell, W. H., 3rd: The thigh-lacer: ambulatory non-operative treatment of femoral shaft fractures. $J$ Bone Joint Surg Am, 60(1): 112-7, 1978.

12. Della Rocca, G. J.; Leung, K. S.; and Pape, H. C.: Periprosthetic fractures: epidemiology and future projections. J Orthop Trauma, 25 Suppl 2: S66-70, 2011.

13. Demos, H. A.; Briones, M. S.; White, P. H.; Hogan, K. A.; and Barfield, W. R.: A biomechanical comparison of periprosthetic femoral fracture fixation in normal and osteoporotic cadaveric bone. $J$ Arthroplasty, 27(5): 783-8, 2011.

14. Dennis, M. G.; Simon, J. A.; Kummer, F. J.; Koval, K. J.; and Di Cesare, P. E.: Fixation of periprosthetic femoral shaft fractures: a biomechanical comparison of two techniques. J Orthop Trauma, 15(3): 177-80, 2001.

15. Dennis, M. G.; Simon, J. A.; Kummer, F. J.; Koval, K. J.; and DiCesare, P. E.: Fixation of periprosthetic femoral shaft fractures occurring at the tip of the stem: a biomechanical study of 5 techniques. $J$ Arthroplasty, 15(4): 523-8, 2000.

16. Ellis, T.; Bourgeault, C. A.; and Kyle, R. F.: Screw position affects dynamic compression plate strain in an in vitro fracture model. J Orthop Trauma, 15(5): 333-7, 2001.

17. Fitzgerald, R.; Brindley, G.; and Kavanagh, B.: The uncemented total hip arthroplasty: intraoperative femoral fractures. Clin Orthop Relat Res, 235: 61, 1988.

18. Fouad, H.: Assessment of function-graded materials as fracture fixation bone-plates under combined loading conditions using finite element modelling. Med Eng Phys, 33(4): 456-63, 2011. 
19. Fredin, H. O.; Lindberg, H.; and Carlsson, A. S.: Femoral fracture following hip arthroplasty. Acta Orthop Scand, 58(1): 20-2, 1987.

20. Fulkerson, E.; Koval, K.; Preston, C. F.; Iesaka, K.; Kummer, F. J.; and Egol, K. A.: Fixation of periprosthetic femoral shaft fractures associated with cemented femoral stems: a biomechanical comparison of locked plating and conventional cable plates. J Orthop Trauma, 20(2): 89-93, 2006.

21. Gehrig, L.; Lane, J.; and O'Connor, M. I.: Osteoporosis: management and treatment strategies for orthopaedic surgeons. J Bone Joint Surg Am, 90(6): 1362-74, 2008.

22. Hall, M. J.; DeFrances, C. J.; Williams, S. N.; Golosinskiy, A.; and Schwartzman, A.: National Hospital Discharge Survey: 2007 summary. Natl Health Stat Report, (29): 1-20, 24, 2010.

23. Hardy, A. E.: The treatment of femoral fractures by cast-brace application and early ambulation. A prospective review of one hundred and six patients. J Bone Joint Surg Am, 65(1): 56-65, 1983.

24. Laurer, H. L.; Wutzler, S.; Possner, S.; Geiger, E. V.; El Saman, A.; Marzi, I.; and Frank, J.: Outcome after operative treatment of Vancouver type B1 and C periprosthetic femoral fractures: open reduction and internal fixation versus revision arthroplasty. Arch Orthop Trauma Surg, 131(7): 983-9, 2011.

25. Lever, J. P.; Zdero, R.; Nousiainen, M. T.; Waddell, J. P.; and Schemitsch, E. H.: The biomechanical analysis of three plating fixation systems for periprosthetic femoral fracture near the tip of a total hip arthroplasty. J Orthop Surg Res, 5: 45, 2010.

26. Lindahl, H.; Malchau, H.; Herberts, P.; and Garellick, G.: Periprosthetic femoral fractures classification and demographics of 1049 periprosthetic femoral fractures from the Swedish National Hip Arthroplasty Register. J Arthroplasty, 20(7): 857-65, 2005.

27. Lindahl, H.; Malchau, H.; Oden, A.; and Garellick, G.: Risk factors for failure after treatment of a periprosthetic fracture of the femur. J Bone Joint Surg Br, 88(1): 26-30, 2006.

28. Lowrey, C.; Nord, K.; Wilson, M.; and Trick, L.: Periprosthetic femur fractures: a complication of rigid cylindrical reaming. Orthop Trans, 15: 342-52, 1991.

29. Moazen, M.; Jones, A. C.; Jin, Z.; Wilcox, R. K.; and Tsiridis, E.: Periprosthetic fracture fixation of the femur following total hip arthroplasty: a review of biomechanical testing. Clin Biomech (Bristol, Avon), 26(1): 13-22, 2011.

30. Parvizi, J.; Jain, N.; and Schmidt, A. H.: Periprosthetic knee fractures. J Orthop Trauma, 22(9): 663-71, 2008.

31. Perren, S.; Fernandez, D. A.; Lenz, M.; and Windolf, M.: Cerclage, evolution and potential of a Cinderella technology. An overview with reference to periprosthetic fractures. Acta Chir Orthop Traumatol Cech, 78(3): 190-9, 2011.

32. Rayan, F., and Haddad, F.: Periprosthetic femoral fractures in total hip arthroplasty - a review. Hip Int, 20(4): 418-26, 2010.

33. Ricci, W. M.; Bolhofner, B. R.; Loftus, T.; Cox, C.; Mitchell, S.; and Borrelli, J., Jr.: Indirect reduction and plate fixation, without grafting, for periprosthetic femoral shaft fractures about a stable intramedullary implant. J Bone Joint Surg Am, 87(10): 2240-5, 2005.

34. Rommens, P.; Endrizzi, D.; Blum, J.; and White, R.: Humerus: shaft. In AO principles of fracture management, pp. 295-309. Edited by Rüedi, T., and Murphy, W., 295-309, New York, AO Publishing, 2000.

35. Rupprecht, M.; Sellenschloh, K.; Grossterlinden, L.; Puschel, K.; Morlock, M.; Amling, M.; Rueger, J. M.; and Lehmann, W.: Biomechanical evaluation for mechanisms of periprosthetic femoral fractures. $J$ Trauma, 70(4): E62-6, 2011.

36. Scott, R. D.; Turner, R. H.; Leitzes, S. M.; $\quad$ and Aufranc, O. E.: Femoral fractures in conjunction with total hip replacement. J Bone Joint Surg Am, 57(4): 494-501, 1975. 
37. Shah, S.; Kim, S. Y.; Dubov, A.; Schemitsch, E. H.; Bougherara, H.; and Zdero, R.: The biomechanics of plate fixation of periprosthetic femoral fractures near the tip of a total hip implant: cables, screws, or both? Proc Inst Mech Eng H, 225(9): 845-56, 2011.

38. Stoffel, K.; Dieter, U.; Stachowiak, G.; Gachter, A.; and Kuster, M. S.: Biomechanical testing of the LCP - how can stability in locked internal fixators be controlled? Injury, 34 Suppl 2: B11-9, 2003.

39. Streit, M. R.; Merle, C.; Clarius, M.; and Aldinger, P. R.: Late peri-prosthetic femoral fracture as a major mode of failure in uncemented primary hip replacement. J Bone Joint Surg Br, 93(2): 178-83, 2011.

40. Talbot, M.; Zdero, R.; and Schemitsch, E. H.: Cyclic loading of periprosthetic fracture fixation constructs. J Trauma, 64(5): 1308-12, 2008.

41. Thomas, T. L., and Meggitt, B. F.: A comparative study of methods for treating fractures of the distal half of the femur. J Bone Joint Surg Br, 63-B(1): 3-6, 1981.

42. Tower, S. S., and Beals, R. K.: Fractures of the femur after hip replacement: the Oregon experience. Orthop Clin North Am, 30(2): 235-47, 1999.

43. Uhthoff, H. K.; Poitras, P.; and Backman, D. S.: Internal plate fixation of fractures: short history and recent developments. J Orthop Sci, 11(2): 118-26, 2006.

44. Weppe, F.; Magnussen, R. A.; Lustig, S.; Demey, G.; Neyret, P.; and Servien, E.: A biomechanical evaluation of bicortical metal screw fixation versus absorbable interference screw fixation after coracoid transfer for anterior shoulder instability. Arthroscopy, 27(10): 1358-63, 2011.

45. Wingerter, S.; Calvert, G.; Tucci, M.; Benghuzzi, H.; Russell, G.; and Puckett, A.: Mechanical strength repercussions of various fixative storage methods on bone. Biomed Sci Instrum, 42: 290-5, 2006.

46. Younger, A. S.; Dunwoody, I.; and Duncan, C. P.: Periprosthetic hip and knee fractures: the scope of the problem. Instr Course Lect, 47: 251-6, 1998.

47. Zdero, R.; Walker, R.; Waddell, J. P.; and Schemitsch, E. H.: Biomechanical evaluation of periprosthetic femoral fracture fixation. J Bone Joint Surg Am, 90(5): 1068-77, 2008. 